\title{
Fabrication of Nickel Coatings on Zirconia Balls by Mechanical Ball Milling and the Process Analysis
}

\author{
Lijia CHEN, Haibin CHEN*, Rongyong LI, Weifeng HE, Yuhui YANG
}

School of Mechanical Engineering, Dongguan University of Technology, No.1 Daxue Rd, Songshan Lake, Dongguan, 523800, China

crossref http://dx.doi.org/10.5755/j02.ms.25977

Received 04 May 2020; accepted 03 June 2020

\begin{abstract}
The Ni coatings were prepared from nickel metal powder and zirconia ceramic balls by mechanical coating technique. The relationship between rotation speed and coatings thickness was studied, the thickness of the coatings was characterized by the weight increase of the zirconia balls after mechanical coating. The composition and microstructure of the coatings with maximum thickness were analyzed by scanning electron microscope (SEM), energy dispersive spectroscopy (EDS), and $\mathrm{X}$-ray Diffraction (XRD). The results revealed that the formation of coatings consists of thickening from the cold welding between Ni particles and the thinning from the exfoliation of coatings work hardening. The thickness of the coatings reaches the maximum when the above two process progress are close to each other. The results proved that higher speed was favor of the coatings formation, the maximum thickness was obtained at the $15 \mathrm{~h}$ for rotation speed of $240 \mathrm{rpm}$, and microscopic images show that the average thickness was about $20 \mu \mathrm{m}$.

Keywords: mechanical coating technique, rotation speed, cold welding, Ni coatings.
\end{abstract}

\section{INTRODUCTION}

In the process of preparing materials by mechanical ball milling, due to the continuous impact and friction of the milling balls, the powder gradually adheres to the surface of the milling balls and causes unavoidable contamination at the end of the process. Recently, ball milling, which is well known for mechanical alloying, has found a new application for mechanical coating using the basic principle of the above contamination phenomenon. If the appropriate process parameters were adopted, several functional coatings have been successfully prepared on the surface of the ball milling medium including ceramic or metal substrates [1-5]. On the one hand, the prepared surface coatings can improve the surface properties of the base material, such as hardness. On the other hand, the milling balls can be used as a coating substrate to prepare available functional coatings materials. Among them, the latter has been favored by many researchers in recent years [6-11], and a coating method called Mechanical Coating Technology (MCT) has been developed. Yoshida et al. [6] used this technique to apply a Ti metal coatings on the surface of the $\mathrm{Al}_{2} \mathrm{O}_{3}$ milling balls, and then obtained a $\mathrm{TiO}_{2}$ coatings by subsequent oxidation. The coatings have an excellent photocatalytic performance and non-toxic. However, the wide application of $\mathrm{TiO}_{2}$ was restricted by its wide band gap, and fast electron-hole recombination. In order to further improve the photocatalytic performance of $\mathrm{TiO}_{2}$ coatings and promote its wide applications, they used a two-step mechanical coating technology (2-Step MCT) to prepare a double-layer composite coatings. Firstly, metal coatings were formed on milling balls using metal powder and ceramic balls were separately as the coating materials and substrate by MCT, and then the $\mathrm{TiO}_{2}$ powder was used as the coating material, and the second layer of the oxide coatings, such as $\mathrm{TiO}_{2}$, was prepared on the ceramic balls to which the metal coatings has been attached, a double layered coatings has been formed, such as $\mathrm{TiO}_{2} / \mathrm{Ti}$ or $\mathrm{TiO}_{2} / \mathrm{Cu}$, etc. [6-8]. In recent years, attention has been paid to improving the photocatalytic performance of $\mathrm{TiO}_{2}$ by doping $\mathrm{Ni}$, and reports on whether $\mathrm{Ni}$ and $\mathrm{TiO}_{2}$ can be double-layered like $\mathrm{TiO}_{2} / \mathrm{Cu}$ are scarce [13-15].

In this work, metal Ni powder was used as raw material to prepare Ni coatings on the surface of $\mathrm{ZrO}_{2}$ ceramic balls by MCT. In order to explore the coating process of metal $\mathrm{Ni}$ forming coatings on ceramic milling balls, the present study focused on the influence of the processing parameters including rotation speed and milling time on the formation of the Ni coatings. Furthermore, the bonding performance between the coatings and the substrate was also studied, and a exfoliation phenomenon after sintering was proposed to describe the bonding strength.

\section{EXPERIMENTAL}

\subsection{Fabrication of $\mathrm{Ni}$ coatings}

Powder of nickel (Ni) metal was used to prepare coatings on the surface of $\mathrm{ZrO}_{2}$ ceramic balls by mechanical coating method, the metal powder as the coating material and ceramic balls as the substrate during this experiment. The ball-to-powder ratio (weight ratio of $\mathrm{ZrO}_{2}$ milling balls to metal Ni powder) was set at 3:5, a total of $80 \mathrm{~g}$ was put into a bowl made of alumina with a volume of $250 \mathrm{~mL}$, and then the mechanical coating was performed by a planetary ball mill. The coating schematically is shown in Fig. 1. In the process, the bowls rotates around their own axes and the rotating support disk rotate simultaneously to accelerate the

\footnotetext{
* Corresponding author. Tel.: +86-769-22861622.

E-mail address: hbchen@dgut.edu.cn (H. Chen)
} 
grinding balls and powder in the bowls. To study the influence of the milling time and the rotation speed on the formation of Ni coatings, the rotation speeds were fixed at 210, 240 and $270 \mathrm{rpm}$ (revolutions per minute), and the milling operation was carried out for 5, 10, 15 and $20 \mathrm{~h}$ from the start of the milling operation. During the fabrication, milling operation was performed 10 min followed by 2 min intermittence to avoid the overheating of the bowl and ensure a stable temperature. The raw materials used to prepare the coatings relevant parameters are listed in Table 1. To evaluate the bonding strength between $\mathrm{Ni}$ coatings and $\mathrm{ZrO}_{2}$ balls substrate, the balls coated with $\mathrm{Ni}$ metal powder were sintered, and the larger the exfoliation amount of $\mathrm{Ni}$ powder is, the weaker the adhesion is.

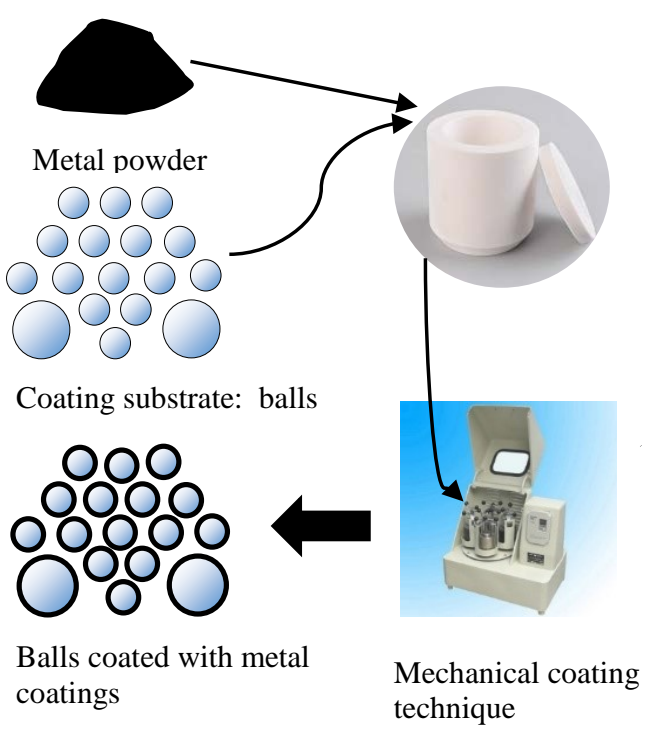

Fig. 1. Schematic diagram of mechanical coating technique

Table 1. Source materials for experimental

\begin{tabular}{|c|c|c|c|}
\hline Materials & Size & Density & Purity, pct \\
\hline $\mathrm{ZrO}_{2}$ balls & $\varnothing 1 \mathrm{~mm}$ & $6.0 \mathrm{~g} \cdot \mathrm{cm}^{-3}$ & $>95.0 \%$ \\
\hline $\mathrm{Ni}$ powders & $75 \mu \mathrm{m}$ & $8.9 \mathrm{~g} \cdot \mathrm{cm}^{-3}$ & $>99.5 \%$ \\
\hline
\end{tabular}

\subsection{Characterization}

The weight of the milling balls was graduallyincreased due to the attachment of metal powder on its surface. In the experiment, the average weight increase of the $\mathrm{ZrO}_{2}$ balls was used to indicate the amount of $\mathrm{Ni}$ powder deposited on the surface of the $\mathrm{ZrO}_{2}$ balls, that is, the larger the weight of the $\mathrm{ZrO}_{2}$ balls after mechanical coating, the greater the thickness of the coatings. However, when the $\mathrm{ZrO}_{2}$ balls filling into the bowl, there is no guarantee that the $\mathrm{ZrO}_{2}$ balls makes the weight exactly $30 \mathrm{~g}$. In order to minimize the error in calculation result, the number of the balls wasfixed for each experiment, and the average weight increase rate of all milling balls was used to replace the weight increase. Finally, scanning electron microscope (SEM) (S-3400N, made by Hitachi Company of Japan) was used to observe the surface morphologies and the microstructure of the cross-sections of the Ni-coated $\mathrm{ZrO}_{2}$ balls with the largest average weight increase rate, the composition in the surface layer of $\mathrm{Ni}$ coatings on $\mathrm{ZrO}_{2}$ balls was measured in SEM by EDS, and X-ray diffraction (XRD) (DX-2500, made by
Haoyuan Company of China) with $\mathrm{Cu}-\mathrm{K} \alpha$ radiation at $25 \mathrm{kV}$ and $15 \mathrm{~mA}$ was used to characterize the coatings phase component before and after sintering treatment.

\section{RESULTS AND DISCUSSION}

\subsection{Influence of the milling time and the rotation speed}

The weight increase of the $\mathrm{ZrO}_{2}$ balls due to more $\mathrm{Ni}$ powder particles coat the balls' surface during mechanical coating at different revolution speeds for different time, was recorded as illustrated in Fig. 2. The weight increase means $\mathrm{Ni}$ coatings formation and thickening. We found that the weight increases of the $\mathrm{ZrO}_{2}$ balls after milling at different speeds for 5 h was: $270 \mathrm{rpm}>240 \mathrm{rpm}>210 \mathrm{rpm}$. It can be seen that the weight of the milling balls increased with the increase in rotation speed, it is beneficial to the thickening of the coatings. As the coating process continues, the weight increase rate of the milling balls after 5 h shows a trend that the rotation speed of $240 \mathrm{rpm}$ increases faster than that of $210 \mathrm{rpm}$. However, when the rotation speed was increased to $270 \mathrm{rpm}$, the weight of the milling balls begun to decrease with the increase of coating time.

On the one hand, increasing the rotation speed increases the milling balls' movement and the kinetic energy of the single milling ball. Therefore, local temperature of powder particles was increased quickly because more energy was transferred during the impact of milling balls, which creates the powder particles were deformed and cold welded, and the coating rate was accelerated. On the other hand, due to the increased impacts frequency of the milling balls in the same time period, more powder particles began to move and adhere to the surface of the milling balls under the impact of the milling balls, accelerating the formation of the coatings. This suggests that a higher revolution speed can accelerate the coating of Ni powder particles on the surface of milling balls, which is consistent with the results of other studies $[16,17]$.

It has been reported that the cold welding and fracturing of the metal powder particles are two opposite processes that occur simultaneously during the mechanical ball milling coating. In other words, the coating was exfoliated from the substrate, there is still powder that continues to be cold welded to the surface of the milling balls, that is, formation and exfoliation of coating occur at the same time. In the theory, the coating thickness will remain unchanged if the rate of the above two processing reaches equilibrium. However, the Ni coatings cannot form a diffusive bond with the surface of the balls due to the $\mathrm{ZrO}_{2}$ ceramics with a high hardness, resulting in the Ni coatings and the milling balls are only mechanically bonded, the bonding was weak. Furthermore, the coatings got work-hardened and become brittle under the repeating sever plastic deformation during long time of ball milling operation. Subsequently, most parts of the metal coatings peeled off from the surface of the ceramic balls and its thickness decreases [11]. It can be seen that the thickness of the coatings has gone through two stages of thickening and thinning [12], which is consistent with other reports [11]. In the present experiment, when the rotation speed was $270 \mathrm{rpm}$, the exfoliation stage started earlier. When the rotation speed was $240 \mathrm{rpm}$, the 
exfoliation started after $15 \mathrm{~h}$ of ball milling, and when the rotation speed was $210 \mathrm{rpm}$, it was still in the formation and thickening stage of coatings even after $20 \mathrm{~h}$ of ball milling.

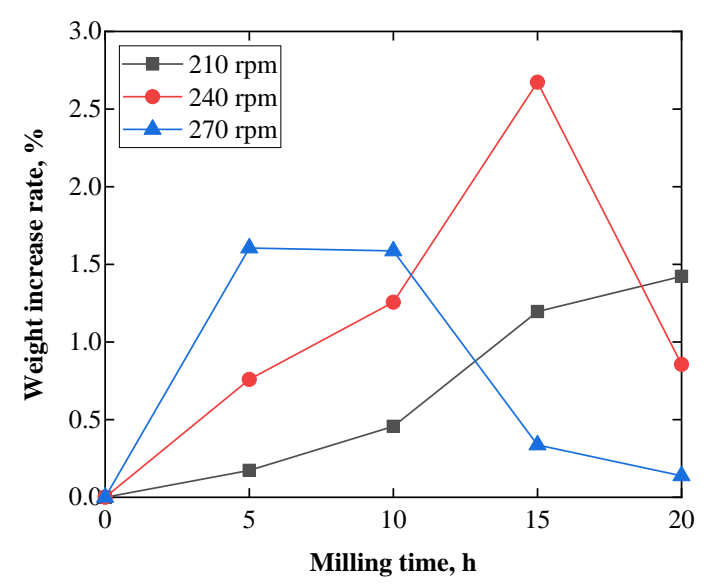

Fig. 2. Weight increase rate of milling balls versus duration of mechanical coating at different revolution speeds

Fig. 3 shows the surface morphology and microstructure of the cross sections of the $\mathrm{ZrO}_{2}$ balls with the maximum weight increase after coating different milling time at different rotation speeds, that is, Fig. $3 \mathrm{a}, \mathrm{d}$, Fig. 3 b, e and Fig. 3 c, f are the corresponding morphology and cross section views after $210 \mathrm{rpm}$ ball milling for $20 \mathrm{~h}$, $240 \mathrm{rpm}$ ball milling for $15 \mathrm{~h}$ and $270 \mathrm{rpm}$ ball milling for $5 \mathrm{~h}$, respectively. The dark gray areas of the balls correspond to zirconia, while bright white regions were confirmed to be nickel. It can be seen from Fig. 3 a that the surface of the $\mathrm{ZrO}_{2}$ balls is not completely covered with white $\mathrm{Ni}$ particles, but only some $\mathrm{Ni}$ metal particles are dispersed on its surface, indicating that dense Ni coatings could not be obtained. The corresponding cross section in Fig. $3 \mathrm{~d}$ shows that a small amount of $\mathrm{Ni}$ particles is locally dispersed on the outside of the $\mathrm{ZrO}_{2}$ balls, and no continuous coatings was formed. Compared with Fig. 3 a, the surface of the $\mathrm{ZrO}_{2}$ balls in Fig. $3 \mathrm{~b}$ was covered by more Ni metal particles. Only a small amount of area was not covered, indicating that a dense coating was basically formed. Fig. 3 e shows that a substantially continuous Ni coatings with an average thickness of about $20 \mu \mathrm{m}$ but uneven was formed on the outside of the $\mathrm{ZrO}_{2}$ balls when the milling time came to $15 \mathrm{~h}$ at rotation speed of $240 \mathrm{rpm}$. The percentage of the surface of the balls covered by Ni particles in Fig. 3 c is between Fig. 3 a and Fig. 3 b, but it is clearly different from Fig. 3 a that the particles deposited on the surface of the ball in Fig. 3 a are discretely distributed, and Fig. 3 c has formed a local continuous area. Fig. 3 f shows that although no continuous coatings was formed, more metal particles were deposited, and they start to join locally. Therefore, the rotation speed of $240 \mathrm{rpm}$ is a better choice during in the coating process of $\mathrm{ZrO}_{2}$ balls having a diameter of $1 \mathrm{~mm}$ with the $\mathrm{Ni}$ metal particles, when the weight ratio of the balls is 3:5, a total of $80 \mathrm{~g}$ was placed into a $250 \mathrm{ml}$ bowl. After $15 \mathrm{~h}$ of ball milling, a substantially continuous coatings can be obtained. Compared with other metal coating processes, the resulting Ni coatings peel off earlier and the final thickness is thin, which may be related to the nickel metal with a high electronegativity and poor plasticity [18].

\subsection{Discussion of mechanism of rotation speed affecting coating}

The fact that continuous coatings can not be obtained during the milling operation at $210 \mathrm{rpm}$ and $270 \mathrm{rpm}$ may be explained by the following phenomenon.

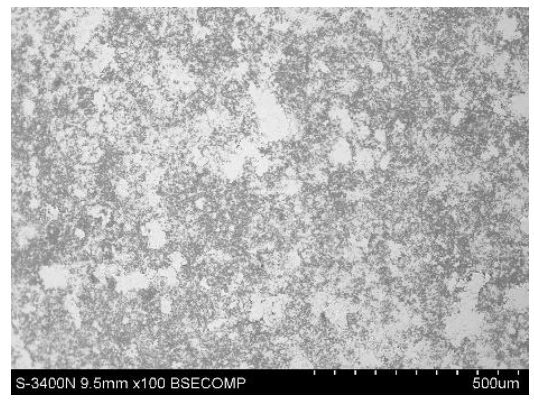

a

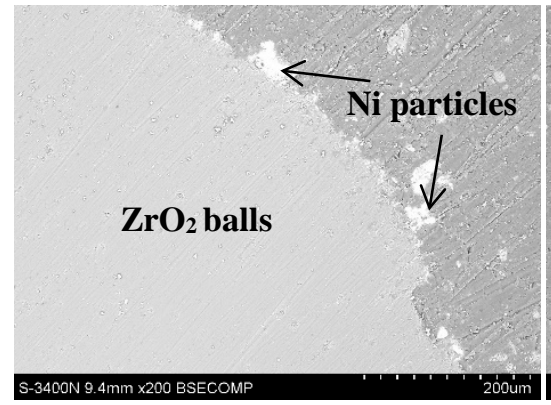

d

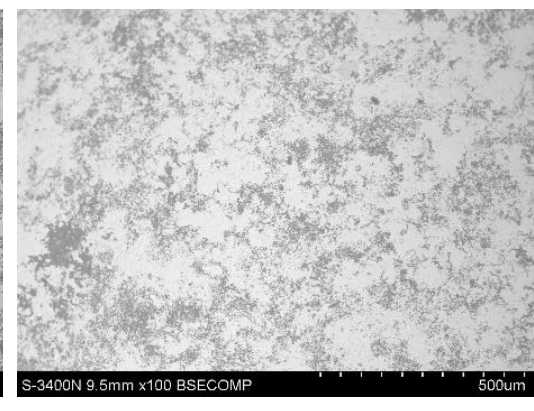

b

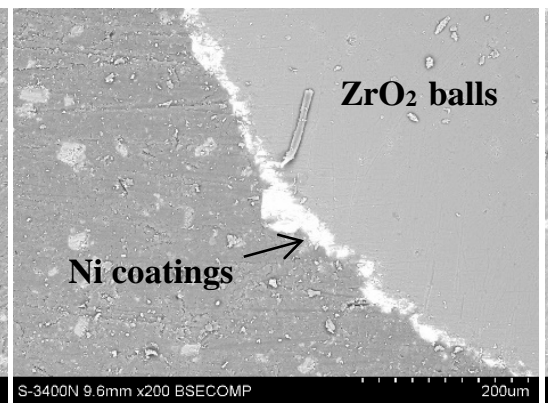

e

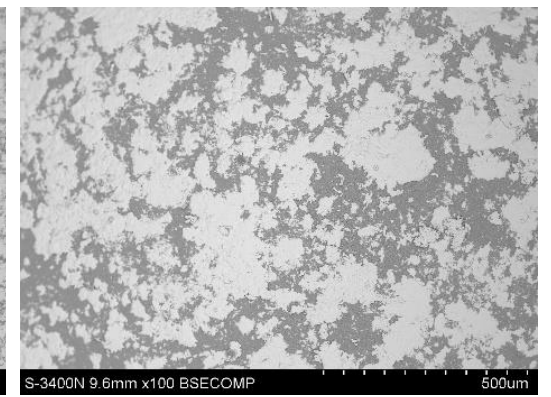

C

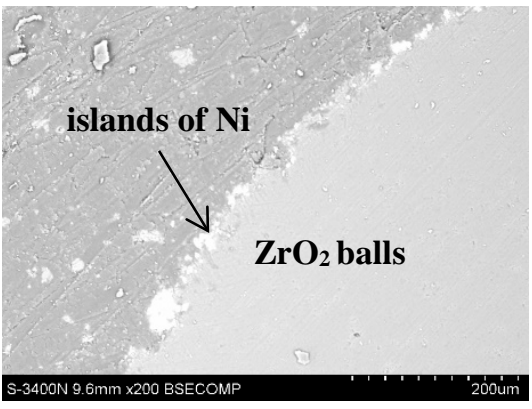

f

Fig. 3. Surface and cross section morphology of $\mathrm{ZrO}_{2}$ balls after: a, d-speed of $210 \mathrm{rpm}$ for $20 \mathrm{~h}$; b, e-speed of $240 \mathrm{rpm}$ for 15 h; c, $\mathrm{f}$ - speed of $270 \mathrm{rpm}$ for $5 \mathrm{~h}$ 
During the milling operation at $210 \mathrm{rpm}$, it was found that the inner wall of the bowl near the top position was clean, indicating that the milling balls and powder began to fall before they reaching the highest position of the top of the bowl. However, with increase in rotation speed up to $270 \mathrm{rpm}$, the inner wall of the bowl and the lid were all contaminated with the powder, but the bottom center of the bowl was as clean as before. In addition, there were obvious spiral dents on the inner surface of the bowl. This observation suggests that the position of the milling balls motion was higher under this condition at $270 \mathrm{rpm}$, and the milling balls were pressed on the inner surface of the bowl. The huge friction between the milling balls and the inner surface of the bowl caused the above spiral dents. The motion track of the milling balls at rotation speed of $210 \mathrm{rpm}$ and $270 \mathrm{rpm}$ was described separately in Fig. 4.

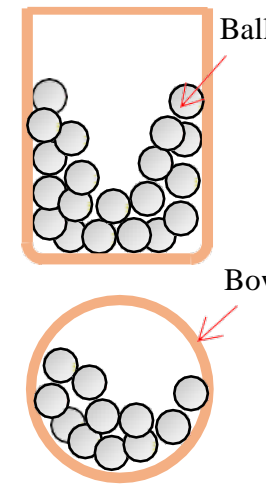

Lower speed

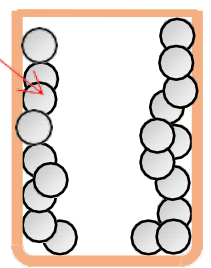

Bowl

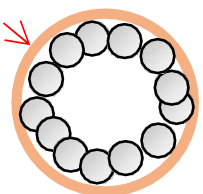

Higher speed
Fig. 4. Simulation of motion of milling balls in different speeds

We might conclude from the above phenomenon that normal force (direct impact force) rather than tangential force (friction force) was dominant during the milling operation at $210 \mathrm{rpm}$. The $\mathrm{Ni}$ metal particles were plastically deformed, cold welded, and deposited on the surface of the milling balls to form a coatings under the action of the impact force from the bowl and the milling balls. On the contrary, with increase in rotation speed up to $270 \mathrm{rpm}$, the motion speed of the milling balls also increases, and the required centripetal force will also increase. In this case, the milling balls will move closely to the inner wall of the milling bowl and losing the impact force, so the formed coatings peels off under the shear of the friction. Indicating that only friction was not conducive to the thickening of the coatings. In summary, the rotation speed might affect the formation of the coatings by changing the stress condition among the metal particles, the milling balls, and the inner wall of bowl [11]. Lower speed mainly produces compressive stress, and higher speed mainly produces shear stress. Increasing the rotation speed within the appropriate range, the coexistence of the two kinds of stresses can significantly shorten the ball milling time and significantly improve the process efficiency, but the continues coatings can not be obtained at excessively high rotation speed.

\subsection{Ni coatings oxidation sintering}

The $\mathrm{ZrO}_{2}$ balls coated with Ni coatings after $15 \mathrm{~h}$ ball milling at $240 \mathrm{rpm}$ were oxidized treatment at $800{ }^{\circ} \mathrm{C}$ in air. The macro-morphology of the balls' surface is shown in Fig. 5. It can be seen from the figure that the $\mathrm{ZrO}_{2}$ balls are no longer white after ball milling, indicating that the surfaces of the balls are almost completely covered with the metal Ni powder. And the surface of the $\mathrm{ZrO}_{2}$ balls after sintering at $800{ }^{\circ} \mathrm{C}$ was light green, which matches the colors of $\mathrm{NiO}$, indicating that $\mathrm{Ni}$ powder might have been oxidized to NiO. In addition, parts of the surface of the milling balls was lighter green and has a whitening phenomenon, indicating that the sintered coatings may be peeled off from the surface of balls, causing the white substrate being exposed.

Fig. 6 is the SEM images of the local microscopic morphology of the $\mathrm{ZrO}_{2}$ balls milled at the optimal rotation speed (240 rpm) for $15 \mathrm{~h}$ and after sintering at $800{ }^{\circ} \mathrm{C}$. As shown from Fig. 6 a, the particles on the surface of the $\mathrm{ZrO}_{2}$ balls showed continuous agglomeration distribution before sintering. Using EDS to perform energy spectrum analysis on these aggregated particles, it was found that these particles were mainly Ni element. In addition, trace amounts of $\mathrm{C}, \mathrm{O}$ and $\mathrm{Al}$ elements may be impurities from corundum bowl and air, and no Zr element was found in EDS results. It might indicate that the milling balls was completely covered by Ni coatings.

However, the particles on the surface of the $\mathrm{ZrO}_{2}$ balls were no longer continuous after sintering was applied in Fig. 6 b, showing a discrete distribution. EDS results show that the particles on the surface of the balls are mainly $\mathrm{O}$ and $\mathrm{Ni}$ elements, indicating that these particles are the $\mathrm{Ni}$ coatings residue rather than the substrate. The analysis is consistent with the above inference that Ni coating has been peeled off after sintering and causes the substrate to be exposed (Fig. 5).

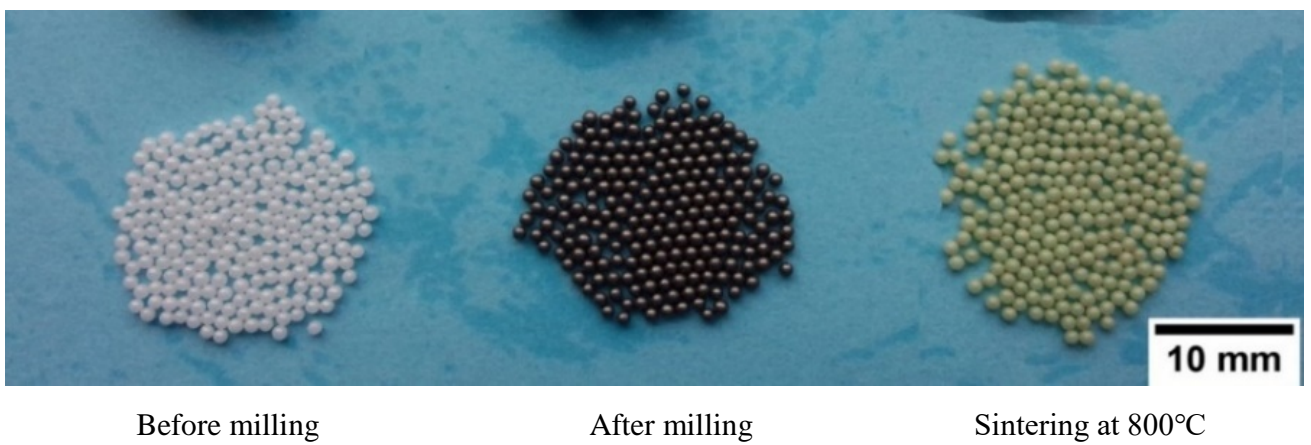

Fig. 5. Surface colors of $\mathrm{ZrO}_{2}$ balls of: before milling, after ball milling for $15 \mathrm{~h}$ at $240 \mathrm{rpm}$, and after oxidation treatment 

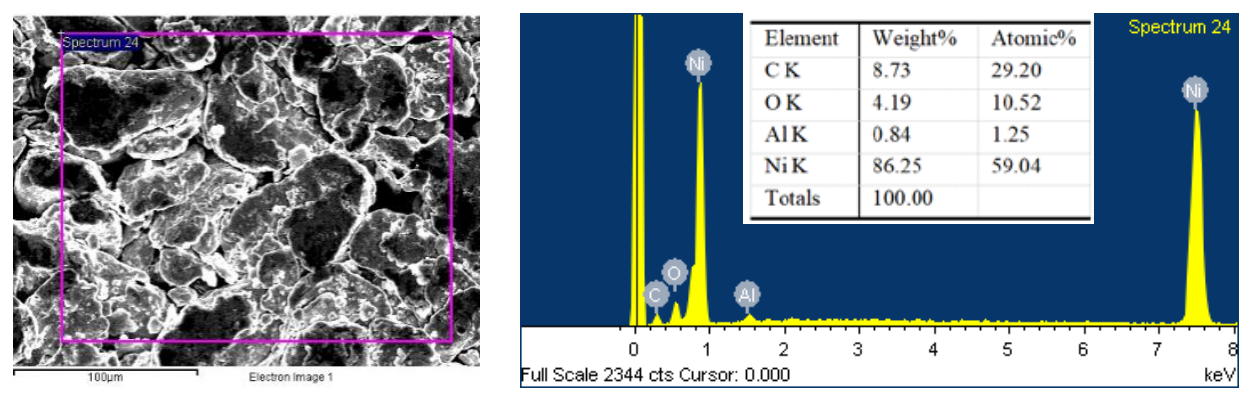

a
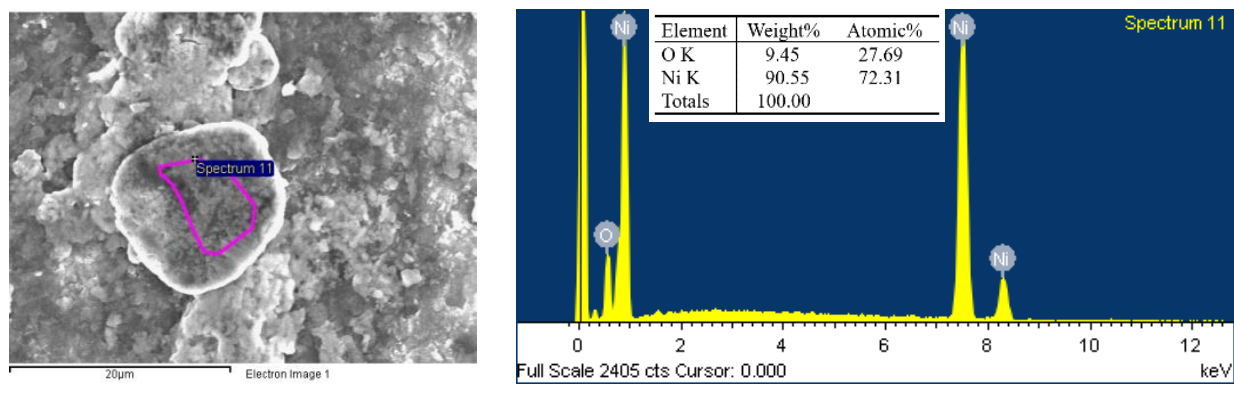

b

Fig. 6. SEM images and EDS of the surface of $\mathrm{ZrO}_{2}$ balls: $\mathrm{a}$ - after ball milling; $\mathrm{b}$-after sintering at $800{ }^{\circ} \mathrm{C}$

The peeling off coatings from the surface of milling balls after heat treatment can be explained by the two reasons as following. On the one hand, the Ni metal particles will leave a large amount of strain energy after suffered severe deformation under the impact of the milling balls, and eventually adhere to the surface of the milling balls to form a coating and leave residual stress. Therefore, the coatings begin to crack and flake after heat treatment. On the other hand, because the thermal expansion coefficients of the metal $\mathrm{Ni}$ and $\mathrm{ZrO}_{2}$ ceramics differ greatly, which causes large thermal stress during sintering and resulting in the coatings to peeled off from the surface of the milling balls [19].

Fig. 7 shows the XRD patterns of the surface of the $\mathrm{ZrO}_{2}$ balls coated with $\mathrm{Ni}$ before and after sintering at $800{ }^{\circ} \mathrm{C}$. It can be seen that diffraction peaks of $\mathrm{NiO}$ became higher, while those of the Ni became lower after sintering. It suggests that $\mathrm{Ni}$ was oxidized to $\mathrm{NiO}$ after sintering at $800{ }^{\circ} \mathrm{C}$ which correspond to Fig. 5 .

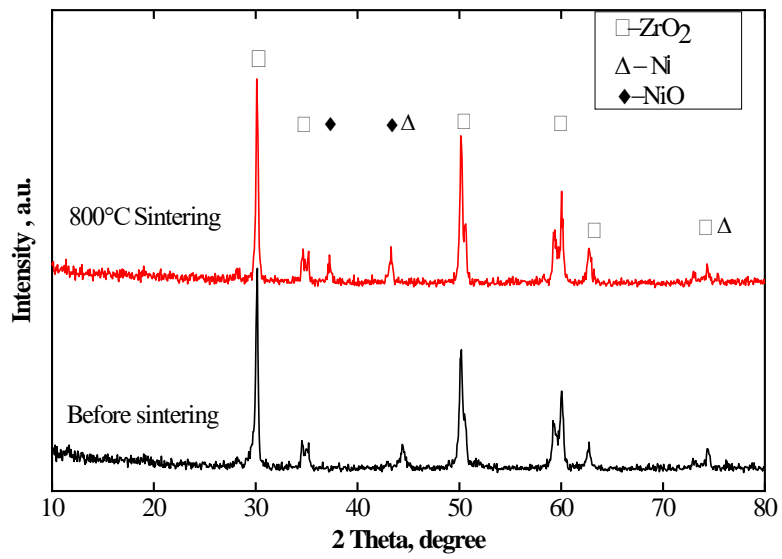

Fig. 7. XRD patterns of the Ni-coated $\mathrm{ZrO}_{2}$ balls before and after sintering at $800{ }^{\circ} \mathrm{C}$
In addition, it is obvious to find that there are $\mathrm{ZrO}_{2}$ diffraction peaks before and after sintering, which may be that the coated Ni coatings is not dense enough before sintering, $\mathrm{X}$-rays directly pass through the gap of the $\mathrm{Ni}$ coatings and diffract with $\mathrm{ZrO}_{2}$. On the other hand, the coatings have a lot of exfoliation after sintering, causing the $\mathrm{ZrO}_{2}$ substrate was bared outside. It is consistent with the phenomena described in Fig. 3 b and Fig. 6 b. However, in the coating process of other metals with better plasticity, the obtained coatings not only have a greater thickness but also have not peeled off significantly after sintering. From the above results, it can be confirmed that the metal $\mathrm{Ni}$ is not suitable for coating directly on the $\mathrm{ZrO}_{2}$ ceramic balls because its bonding strength with the substrate is relatively poor, a composite coatings like $\mathrm{TiO}_{2} / \mathrm{Ni}$ might be obtained by first preparing a $\mathrm{TiO}_{2}$ coatings and then coating $\mathrm{Ni}$ coatings on its surface.

\section{CONCLUSIONS}

In the process of preparing Ni coatings on the surface of $\mathrm{ZrO}_{2}$ ceramic balls by mechanical ball milling coating method, the formation of the coatings was a dynamic process of the cold welding between metal particles and the exfoliation of coatings were made. The evolution of the coatings' thickness can fall into thickening and thinning stages, higher rotation speed greatly accelerated the evolution of the coatings by increasing the collision strength of the balls. However, when the rotation speed was too high, the maximum thickness of the coatings was smaller, a critical minimum rotation speed was required to form continuous Ni coatings. Continuous Ni coatings with an average thickness of $20 \mu \mathrm{m}$ was fabricated by mechanical coating technique during rotation at $240 \mathrm{rpm}$ for $15 \mathrm{~h}$, the coatings have a low dense and poor adhesion to the substrate. Therefore, metal Ni is not suitable for mechanical milling directly on ceramic balls to form an ideal coatings, 
a composite coatings such as $\mathrm{TiO}_{2} / \mathrm{Ni}, \mathrm{TiO}_{2} / \mathrm{NiO}$ may be obtained by first preparing a $\mathrm{TiO}_{2}$ coatings and then coating $\mathrm{Ni}$ on its surface.

\section{Acknowledgements}

This work was supported by the financial support of the Dongguan Social Science and Technology Development Project (Grant No. 2019507140209 and 2019507140843), the Natural Science Foundation of Guangdong Province (Grant No. 2020A1515010814), the characteristic innovation projects of general colleges and universities in Guangdong Province (Grant No. 2018KTSCX223), the young team project of DGUT (Grant No. TDQN2019003).

\section{REFERENCES}

1. Farahbakhsh, I., Zakeri, A., Manikandan, P., Tanaka, S., Hokamoto, K. Effect of Mechanical Alloying Parameters on the Formation of Ni-Cu Solid Solution Coating on the Ni Balls Japanese Journal of Applied Physics 50 (1) 2011: pp. 01BE06(1-7). https://doi.org/10.1143/JJAP.50.01BE06

2. Chen, C.L., Suprianto. Microstructure and Mechanical Properties of AlCuNiFeCr High Entropy Alloy Coatings by Mechanical Alloying Surface and Coatings Technology 386 2020: pp. $125443-125450$.

https://doi.org/10.1016/j.surfcoat.2020.125443

3. Jiang, J., Feng, X.M., Shen, Y.F., Lu, C.Y., Tian, Y. Oxidation Behavior of Cr-AlSi12 Composite Coatings on Ti6Al-4V Alloy Substrate Fabricated via High-energy Mechanical Alloying Method Surface \& Coatings Technology 367 2019: pp. 212-224. https://doi.org/10.1016/j.surfcoat.2019.03.070

4. Yan, C., Xiong, D., Li, J.L. Synthesis of Ni-Al-Ta Composite Coatings on Al Alloy Plates and the Transfer of Al Powder via Mechanical Milling Technique Powder Technology 340 2018: pp. 234-242.

https://doi.org/10.1016/j.powtec.2018.09.024

5. Farahbakhsh, I., $\quad$ Zakeri, A., $\quad$ Manikandan, P., Hokamoto, K. Evaluation of Nanostructured Coating Layers Formed on $\mathrm{Ni}$ Balls During Mechanical Alloying of $\mathrm{Cu}$ Powder Applied Surface Science 257 (7) 2011: pp. 2830 - 2837.

https://doi.org/10.1016/j.apsusc.2010.10.071

6. Yoshida, H., Lu, Y., Nakayama, H., Hirohashi, $\mathbf{M}$. Fabrication of $\mathrm{TiO}_{2}$ Film by Mechanical Coating Technique and its Photocatalytic Activity Journal of Alloys and Compounds $475(1-2)$ 2009: pp. 383-386. https://doi.org/10.1016/j.jallcom.2008.07.059

7. Lu, Y., Hao, L., Toh, K., Yoshida, H. Fabrication of $\mathrm{TiO}_{2} / \mathrm{Cu}$ Composite Photocatalyst Thin Film by 2-step Mechanical Coating Technique and Its Photocatalytic Activity Advanced Materials Research 415-417 2012: pp. $1942-1948$.

https://doi.org/10.4028/www.scientific.net/AMR.415417.1942

8. Lu, Y., Matsuzaka, K., $\quad$ Hao, L., $\quad$ Hirakawa, Y., Yoshida, H., Pan, F.S. Photocatalytic Activity of $\mathrm{TiO}_{2} / \mathrm{Ti}$ Composite Coatings Fabricated by Mechanical Coating Technique and Subsequent Heat Oxidation Materials Science in Semiconductor Processing 16(6)
2013: pp. $1949-1956$.

https://doi.org/10.1016/j.mssp.2013.07.024

9. Tang, X.X., Zha, W.S., Zhang, G.Y., Li, P.P., Tang, J. Effects of Oxidation Temperature on the Microstructure and Photocatalytic Activity of the $\mathrm{TiO}_{2}$ Coating Materials Science (Medziagotyra) 23 (2) 2017: pp. 103-107. https://doi.org/10.5755/j01.ms.23.2.15590

10. Lu, Y., Guan, S.J., Hao, L., Yoshida, H. Review on the Photocatalyst Coatings of $\mathrm{TiO}_{2}$ : Fabrication by Mechanical Coating Technique and Its Application Coatings $5(3)$ 2015: pp. 425-464. https://doi.org/10.3390/coatings5030425

11. Hao, L., Lu, Y., Asanuma, H., Guo, J. The Influence of the Processing Parameters on the Formation of Iron Thin Films on Alumina Balls by Mechanical Coating Technique Journal of Materials Processing Technology 212 (5) 2012: pp. $1169-1176$. https://doi.org/10.1016/j.jmatprotec.2012.01.001

12. Hao, L., Lu, Y., Sato, H., Asanuma, H. Fabrication of Zinc Coatings on Alumina Balls From Zinc Powder by Mechanical Coating Technique and the Process Analysis Powder Technology 228 2012: pp. 377-384. https://doi.org/10.1016/j.powtec.2012.05.056

13. Wang, Q., Qin, Z.N., Chen, J., Ren, B.S., Chen, Q.F., Guo, Y.C., Cao, X.F. Green Synthesis of Nickel Species in Situ Modified Hollow Microsphere $\mathrm{TiO}_{2}$ with Enhanced Photocatalytic Activity Applied Surface Science 364 2016: pp. 1-8. https://doi.org/10.1016/j.apsusc.2015.12.033

14. Jia, J.L., Li, D., Cheng, X.W., Wan, J.F., Yu, X.J. Construction of Graphite/ $/ \mathrm{TiO}_{2} / \mathrm{Nickel}$ Foam Photoelectrode and its Enhanced Photocatalytic Activity Applied Catalysis A-General 525 2016: pp. 128-136. https://doi.org/10.1016/j.apcata.2016.07.010

15. Basavarajappa, P.S., Patil, S.B., Ganganagappa, N., Reddy, K.R., Raghu, A.V., Reddy, C.V. Recent Progress in Metal-doped $\mathrm{TiO}_{2}$, Non-metal Doped/Codoped $\mathrm{TiO}_{2}$ and $\mathrm{TiO}_{2}$ Nanostructured Hybrids for Enhanced Photocatalysis International Journal of Hydrogen Energy 45 (13) 2020: pp. $7764-7778$. https://doi.org/10.1016/j.ijhydene.2019.07.241

16. Hao, L., Yoshida, H., Itoi, T., Lu, Y. Preparation of Metal Coatings on Steel Balls Using Mechanical Coating Technique and Its Process Analysis Coatings 7 (4) 2017: pp. 53-62. https://doi.org/10.3390/coatings7040053

17. Hao, L., Lu, Y., Sato, H., Asanuma, H., Guo, J. Analysis on Energy Transfer During Mechanical Coating and Ball milling- Supported by Electric Power Measurement in Planetary Ball Mill International Journal of Mineral Processing 121 2013: pp. 51-58. https://doi.org/10.1016/j.minpro.2013.03.003

18. Hao, L., Lu, Y., Sato, H., Asanuma, H., Guo, J. Influence of Metal Properties on the Formation and Evolution of Metal Coatings During Mechanical Coating Metallurgical and Materials Transactions A-physical Metallurgy and Materials Science 44A(6) 2013: pp. 2717-2724. https://doi.org/10.1007/s11661-013-1632-z

19. Zhou, W.B., Zhang, R.B., Ai, S.G., Pei, Y.M., Fang, D.N. Analytical Modeling of Thermal Residual Stresses and Optimal Design of $\mathrm{ZrO}_{2} /\left(\mathrm{ZrO}_{2}+\mathrm{Ni}\right)$ Sandwich Ceramics Ceramics International 41 (6) 2013: pp. 8142-8148. https://doi.org/10.1016/j.ceramint.2015.03.025 